NBER WORKING PAPER SERIES

\title{
THE "NEWS" VIEW OF ECONOMIC FLUCTUATIONS: EVIDENCE FROM AGGREGATE JAPANESE DATA AND SECTORAL U.S. DATA
}

\author{
Paul Beaudry \\ Franck Portier \\ Working Paper 11496 \\ http://www.nber.org/papers/w11496
NATIONAL BUREAU OF ECONOMIC RESEARCH
1050 Massachusetts Avenue
Cambridge, MA 02138
June 2005

\begin{abstract}
A first version of this paper was prepared for the $17^{\text {th }}$ Annual TRIO (NBER-CEPR-TCER) conference at Keio University, Tokyo, Japan. We wish to thank the participants to the TRIO conference and our discussants Sadao Nagaoka and Jiro Nemoto for their comments. We are indebted to Toni Braun, Fumio Hayashi and Tsutomu Miyagawa for kindly providing us with some data and information about availability and construction of Japanese aggregate TFP series. We have also benefitted from the comments of the editor Takeo Hoshi. The usual disclaimer applies. The views expressed herein are those of the author(s) and do not necessarily reflect the views of the National Bureau of Economic Research.
\end{abstract}

(C)2005 by Paul Beaudry and Franck Portier. All rights reserved. Short sections of text, not to exceed two paragraphs, may be quoted without explicit permission provided that full credit, including $\odot$ notice, is given to the source. 
The "News" View of Economic Fluctuations: Evidence from Aggregate Japanese Data and Sectoral U.S. Data

Paul Beaudry and Franck Portier

NBER Working Paper No. 11496

July 2005

JEL No. E3

\begin{abstract}
$\underline{\text { ABSTRACT }}$
This paper uses aggregate Japanese data and sectoral U.S. data to explore the properties of the joint behavior of stock prices and total factor productivity $(T F P)$ with the aim of highlighting data patterns that are useful for evaluating business cycle theories. The approach used follows that presented in Beaudry and Portier [2004b]. The main findings are that $(i)$ in both Japan and the U.S., innovations in stock prices that are contemporaneously orthogonal to TFP precede most of the long run movements in total factor productivity and (ii) such stock prices innovations do not affect U.S. sectoral TFPs contemporaneously, but do precede TFP increases in those sectors that are driving U.S. TFP growth, namely durable goods, and among them equipment sectors.
\end{abstract}

Paul Beaudry

Department of Economics

University of British Columbia

Room 997-1873 East Mall

Vancouver, BC V6T 1Z1

CANADA

and NBER

paulbe@interchange.ubc.ca

Franck Portier

GREMAQ-IDEI,

Université des Sciences Sociales

21 Allée de Brienne

F-31042 Toulouse

FRANCE

fportier@cict.fr 


\section{Introduction}

In Beaudry and Portier [2004b], we used U.S. data to document properties of the joint behavior of Total Factor Productivity (hereafter TFP) and stock prices (hereafter $S P$ ) that are supportive of a "news view" of business cycles, that is, a view of business cycles where it is news about future developments in productivity that drive fluctuations. In particular, we presented two orthogonalized moving average representation for these variables: one based on an impact restriction and one based on a long run restriction. We then examined the correlation between the innovations that drive the long run movements in TFP and the stock prices innovation which is contemporaneously orthogonal to TFP. We found this correlation to be positive and almost equal to 1, indicating that permanent changes in productivity growth are preceded by stock market booms. We showed why this observed positive correlation runs counter to that predicted by simple models where surprise changes in productivity drive fluctuations. We also discussed how the pattern could arise if agents have advanced information about future technological opportunities, or if productivity growth emerges as a delayed byproduct of a period high investment activity. In either case, the results suggests that expected changes in technological opportunities may be central to business cycle fluctuations even if surprise changes in productivity are not.

In this paper, we extend this analysis to Japanese aggregate data and U.S. sectoral data. The analysis of aggregate Japanese data confirms our previous results: stock prices innovations do contain most of the information about the long run movements of aggregate TFP, and are responsible for short run business cycle fluctuations. Our econometric setup also allows for an account of the Japanese "lost decade", and shows that a downward revision of TFP growth in 1990 and 1992, which first revealed itself in stock prices, can account for the low performance of TFP and $S P$ in the 1990s.

Second, we analyze the relation between the aggregate U.S. stock prices innovation and the behavior of sectoral manufacturing TFP. Our analysis of U.S. Manufacturing two-digit data shows that the stock prices news is indeed a shock that does not affect sectoral TFPs on impact, but increases TFP in the long run for those sectors that are driving TFP growth, namely durable goods, and among them equipment sectors. 


\section{The Setup}

In this section, we present the tools introduced in Beaudry and Portier [2004b], which can be described as a new way of using orthogonalization techniques -i.e. impact and long run restrictions - to learn about the nature of technological progress diffusion and business cycle fluctuations. Those techniques are not used simultaneously, but sequentially, to describe the joint behavior of stock prices $(S P)$ and measured total factor productivity $(T F P)$.

\subsection{Two Orthogonalization Schemes}

Assume that we have an estimate of the reduced form moving average (Wold) representation for the bivariate system $\left\{T F P_{t}, S P_{t}\right\}$, as given below (for ease of presentation we neglect any drift terms).

$$
\left(\begin{array}{c}
\Delta T F P_{t} \\
\Delta S P_{t}
\end{array}\right)=C(L)\left(\begin{array}{c}
\mu_{1, t} \\
\mu_{2, t}
\end{array}\right)
$$

where $L$ is the lag operator, $C(L)=I+\sum_{i=1}^{\infty} C_{i} L^{i}$, and where the variance co-variance matrix of $\mu$ is given by $\Omega$. Furthermore, we will assume that the system has at least one stochastic trend and therefore $C(1)$ is not equal to zero (this is confirmed by unit roots and cointegration tests for aggregate U.S. and Japanese series).

We want to consider two alternative representations with orthogonalized errors, one that imposes an impact restriction on the representation and one that imposes a long run restriction. Let us denote these two alternative representations by:

$$
\begin{aligned}
& \left(\begin{array}{c}
\Delta T F P_{t} \\
\Delta S P_{t}
\end{array}\right)=\Gamma(L)\left(\begin{array}{c}
\epsilon_{1, t} \\
\epsilon_{2, t}
\end{array}\right), \\
& \left(\begin{array}{c}
\Delta T F P_{t} \\
\Delta S P_{t}
\end{array}\right)=\widetilde{\Gamma}(L)\left(\begin{array}{c}
\widetilde{\epsilon}_{1, t} \\
\widetilde{\epsilon}_{2, t}
\end{array}\right),
\end{aligned}
$$

where $\Gamma(L)=\sum_{i=0}^{\infty} \Gamma_{i} L^{i}, \widetilde{\Gamma}(L)=\sum_{i=o}^{\infty} \widetilde{\Gamma}_{i} L^{i}$ and the variance covariance matrices of $\epsilon$ and $\widetilde{\epsilon}$ are identity matrices. In order to get such a representation, say in the case of (1), we need to find the $\Gamma$ matrices that solve the following system of equations:

$$
\left\{\begin{array}{l}
\Gamma_{0} \Gamma_{0}^{\prime}=\Omega \\
\Gamma_{i}=C_{i} \Gamma_{0} \text { for } i>0
\end{array}\right.
$$

However, since the above system has one more variable than equations, it is necessary to add a restriction to pin down a particular solution. In case (1), we will pin down a solution by imposing that the 1,2 element of $\Gamma_{0}$ be equal to zero, that is, we choose an orthogonalization where the 
second disturbance $\epsilon_{2}$ has no contemporaneous impact on TFP. In case (2), we impose that the 1,2 element of the long run matrix $\widetilde{\Gamma}(1)=\sum_{i=0}^{\infty} \widetilde{\Gamma}_{i}$ equals zero, that is, we choose an orthogonalization where the disturbance $\widetilde{\epsilon}_{2}$ has no long run impact on TFP (the use of this type of orthogonalization was first proposed by Blanchard and Quah [1989]). We will refer to $\epsilon_{2}$ as the stock prices innovation, whereas $\widetilde{\epsilon}_{1}$ will be referred to as the permanent shock to TFP.

\subsection{Some Simple Structural Interpretations}

Here we illustrate the implications of sequentially using impact and long-run restrictions. We do so in a canonical optimal growth model in which technological improvements come either as surprises or are announced in advance, so that agents recognize the potential impact of an innovation before it has improved productivity. We will show that these two models deliver different predictions with respect to the correlation between $\epsilon$ and $\widetilde{\epsilon}$. As we want to derive simple and explicit results, the models we present here do not aim at realism as many assumptions are made in order to allow analytical solutions.

A Simple Optimal Growth Model with Technology and Preference Shocks: Let us consider an economy in which preferences of the representative household are given by

$$
U=E_{0} \sum_{t=0)}^{\infty} \beta^{t}\left[\log C_{t}-\Lambda_{t} \frac{L_{t}^{\sigma}}{\sigma}\right]
$$

where $C$ is consumption, $L$ labor and $\Lambda$ a stationary preference shock.

$$
\Lambda_{t}=e^{\eta_{2, t}}
$$

It is assumed that $\sigma>1$ and that $\beta$ lies inside the unit interval. The preference shock acts here as a "demand" shock. A government spending shock would be a more natural candidate for a demand shock, but the present formulation has the advantage of analytical tractability, and for our purpose, is equivalent to a government spending shock. The household accumulates capital, and we assume full depreciation, so that

$$
K_{t+1}=I_{t}
$$

where $K$ is capital and $I$ investment. The budget constraint of the household, that rents capital and labor services to the representative firm, is given by

$$
C_{t}+I_{t}=w_{t} L_{t}+\kappa_{t} I_{t-1}
$$


where $\kappa$ is the rental rate of capital services and $w$ the wage rate.

The representative firm in this economy produces according to the CRS technology

$$
Y_{t}=e^{\theta_{t}} K_{t}^{\gamma} L_{t}^{1-\gamma}
$$

with $\gamma \in] 0,1[$ and where $\theta$ is a random walk technology shock.

$$
\theta_{t}=\theta_{t-1}+\eta_{1, t}
$$

$\eta_{1, t}$ and $\eta_{2, t}$ are assumed to be iid processes with identity covariance matrix and zero mean.

We assume that agents behave competitively, maximize utility or profit at given prices and that markets clear. In such an economy, as shown in the appendix, the solution is log-linear. With this solution, one can perform the short-run and long-run orthogonalizations we presented above, and recover the shocks $\epsilon$ and $\widetilde{\epsilon}$ as functions of the structural shocks $\eta_{1, t}$ and $\eta_{2, t}$. Since firms make zero profits every period, the stock market value of firms is uninteresting in this model, but there are still asset prices fluctuations in the bond market. Hence, we will focus here on the joint behavior of TFP and the bond price as the system of interest, that is, the bond price will play the role of the variable $S P_{t}$ introduced in the preceding section (the only property that this second variable should have is that it should agglomerate expectations).

In this model, the equilibrium joint behavior of (the $\log$ of) TFP (that is $\theta$ ) and (the $\log$ of) bond price (denoted $p^{b}$ ) has a structural moving average given by:

$$
\left(\begin{array}{c}
\Delta T F P_{t} \\
\Delta p_{t}^{b}
\end{array}\right)=\left(\begin{array}{cc}
1 & 0 \\
\frac{(1-\gamma)}{1-\gamma L}-1 & -\frac{(1-L)(1-\gamma)^{2}}{\sigma(1-\gamma L)}
\end{array}\right)\left(\begin{array}{c}
\eta_{1, t} \\
\eta_{2, t}
\end{array}\right)
$$

Performing short-run and long-run identification on this system, we obtain

$$
\epsilon_{1}=\eta_{1} \quad, \quad \epsilon_{2}=\eta_{2} \quad, \quad \tilde{\epsilon}_{1}=\eta_{1} \quad, \quad \tilde{\epsilon}_{2}=\eta_{2}
$$

In particular, we have $\epsilon_{2} \perp \widetilde{\epsilon}_{1}$.

\section{A Model with One Period Delayed Response of Innovation on Productivity : Let us} now consider a small deviation from the RBC model we just presented. We now assume that $\theta_{t}$ has both a permanent component $-\bar{\theta}_{t}-$ and a temporary component $-\nu_{t}$, and we disregard preference shock so as to keep exactly as many shocks as variables. The important additional assumption is that permanent innovation to technology are known to agents one period before they actually 
impact TFP ${ }^{1}$. The process for (the log of) TFP can therefore be expressed as follows:

$$
\begin{cases}T F P_{t} & =\bar{\theta}_{t}+\nu_{t} \\ \bar{\theta}_{t+1} & =\bar{\theta}_{t}+\eta_{1, t} \\ \nu_{t} & =\rho \nu_{t-1}+\eta_{2, t}, \quad 0<\rho<1\end{cases}
$$

In this model, the structural moving average for TFP and bond prices can be shown to be given by (see the appendix):

$$
\left(\begin{array}{c}
\Delta T F P_{t} \\
\Delta p_{t}^{b}
\end{array}\right)=\left(\begin{array}{cc}
L & \frac{\gamma(1-L)}{(1-\rho L)} \\
\frac{(1-\gamma) L}{1-\gamma L}-1 & \frac{(-\rho)(1-L)}{(1-\rho L)}
\end{array}\right)\left(\begin{array}{l}
\eta_{1, t} \\
\eta_{2, t}
\end{array}\right)
$$

Performing short-run and long-run identification on this system, we obtain

$$
\epsilon_{1}=\eta_{2} \quad, \quad \epsilon_{2}=\eta_{1} \quad, \quad \tilde{\epsilon}_{1}=\eta_{1} \quad, \quad \tilde{\epsilon}_{2}=\eta_{2}
$$

In particular, we have that $\epsilon_{2}$ is co-linear to $\widetilde{\epsilon}_{1}$.

Discussion : In Beaudry and Portier [2004b], we have illustrated the fact that U.S. postwar data are typically displaying co-linearity between $\epsilon_{2}$ and $\widetilde{\epsilon}_{1}$. Such a result favors a view of business cycles driven largely by a shock that does not affect productivity in the short run - and therefore does not look like a standard technology shock - but affects productivity with substantial delay - and therefore does not look like a demand shock. One structural interpretation we have suggested for this shock is that it represents news about future technological opportunities which is first captured in stock prices. We have shown that this shock causes a boom in consumption, investment and hours worked that precedes productivity growth by a few years. In the next section, we show that those results are also found when one study Japanese aggregate data.

\section{Aggregate Analysis For The U.S. and Japan}

\subsection{Data and Specification Issues}

In our empirical investigation, we will make use of annual japanese and US data.

U.S. Data : U.S. data cover the period 1948 to 2000. The two series that interest us for our bivariate analysis are an index of stock market value $(S P)$ and a measure of total factor productivity.

\footnotetext{
${ }^{1}$ Hairault, Langot, and Portier [1997] have proposed the estimation of an informational structure close to that one in an otherwise standard RBC model. In Beaudry and Portier [2004b], we provide an endowment economy example in which we allow for gradual diffusion of the innovation into TFP, instead of this very crude assumption of a one period lag for implementation of the technological shock. In Beaudry and Portier [2004a], we study a more realistic setup in which agents receive noisy signals about future values of productivity growth.
} 
The stock market index we use is the quarterly Standards \& Poors 500 Composite Stock Prices Index, deflated by the seasonally adjusted implicit prices deflator of GDP in the nonfarm private business sector and transformed in per-capita terms by dividing it by the population aged 15 to 64. We denote the $\log$ of this index by $S P$

The construction of our baseline TFP series is relatively standard. We restrict our attention to the nonfarm private business sector. From the U.S. Bureau of Labor Statistics, we retrieved two series: labor share $\left(s_{h}\right)$ and capital services $(K S)$ which measures the services derived from the stock of physical assets and software. The average value of the labor share is $\bar{s}_{h}=67.66 \%$. Output $(Y)$ and hours $(H)$ are nonfarm business measures from 1947 to 2000 (also from U.S. Bureau of Labor Statistics). We then construct a measure of (log) TFP as

$$
T F P_{t}=\log \left(\frac{Y_{t}}{H_{t}^{\bar{s}_{h}} K S_{t}^{1-\bar{s}_{h}}}\right)
$$

Japanese Data : Japanese data cover the period 1960 to 2000. Most are obtained from Hayashi and Prescott ${ }^{2}$, TFP, GNP deflator, age 20-69 population in millions, Total Hours, Consumption (Private consumption) and Investment (Private Fixed Capital Investment). The Hours series have been deflated by the 20-69 population series. The investment and consumption series have been deflated by both GNP deflator and age 20-69 population. The stock prices series is the end-of-year Nikkei 2253 , deflated by the GNP deflator and the age 20-69 population.

Specification: From our data on $T F P$ and $S P$, we first want to recover the Wold moving average representation for $\triangle T F P$ and $\triangle S P$. Unit root tests and cointegration tests (not reported here) indicate that $S P$ and $T F P$ are likely cointegrated I(1) processes, so a natural means of recovering the Wold representation is by inverting a Vector Error Correcting Model (VECM). The second specification choice concerns the number of lags to include in the VECM. Our strategy is not to impose much on the data. According to a likelihood ratio test two lags are chosen for U.S. data and six for Japanese data. We will show that Japanese results are robust to a specification with one or two lags.

\footnotetext{
${ }^{2}$ See Hayashi and Prescott [2002] and the web site http://www.e.u-tokyo.ac.jp/ hayashi/hp/hayashi_prescott.htm for the Excel Files.

${ }^{3}$ As obtained from http://www.finfacts.com/Private/curency/nikkei225performance.htm.
} 


\subsection{Lessons for TFP movements}

We estimated a VECM for $(T F P, S P)$ with one cointegrating relation and recovered two orthogonalized shock series corresponding to the $\epsilon$ and $\widetilde{\epsilon}$ discussed in Section 2, that is, $\epsilon$ was recovered by imposing an impact restriction (a restriction on $\Gamma_{0}$ ) and $\widetilde{\epsilon}$ was recovered by imposing a long run restriction. The level impulse responses on $(T F P, S P)$ associated with the $\epsilon_{2}$ shock and the $\widetilde{\epsilon}_{1}$ shock are displayed on Figure 1. The U.S. results are those presented in Beaudry and Portier [2004b].

The first remarkable result is that for Japanese data as well as for the US ones, those responses appear very similar when comparing one orthogonalization to another. The dynamics associated with the $\epsilon_{2}$ shock - the stock prices innovation that is by construction contemporaneously orthogonal to TFP- seems to permanently affect TFP, while the dynamics associated with the $\widetilde{\epsilon}_{1}$ shock -which by construction has a permanent effect on TFP- has essentially no impact effect on TFP but has a substantial effect on $S P$. On the one hand, these results suggest that $\epsilon_{2}$ contains information about future TFP growth which is instantaneously and positively reflected in stock prices. While on the other hand, they suggest that permanent changes in TFP are first reflected in stock prices before they actually increase productive capacity. From both U.S. and Japanese data, we observe that it takes four to six years for TFP to respond positively in a significant way. Note that those results are robust to the choice of the number of lags in the VECM: Figure 4 shows that the IRF are very close if one imposes one or two lags instead of six.

The similarity between the effects of these two shocks is further confirmed by the inspection of the forecast error variance decomposition plot (Figure 2). Observe that the $\widetilde{\epsilon}_{1}$ shock explains very little of the short run movements of TFP (less than $30 \%$ the first 4 years). On the other hand, the $\epsilon_{2}$ shock explains most of the long run variance of TFP after 30 years ( $80 \%$ for Japan). This result derives from the quasi-identity between the $\epsilon_{2}$ shock and the $\widetilde{\epsilon}_{1}$ shock, as shown in Figure 3 , which simply plots $\epsilon_{2, t}$ against $\widetilde{\epsilon}_{1, t}$. The correlation coefficient between these two series is .98 (with a standard deviation of .03) for the U.S. and .91 (with a standard deviation of .07) for Japan, that is, these two orthogonalization techniques recover virtually the same shock series.

What kind of structural macroeconomic model is consistent with these two orthogonalization techniques generating the same shock series? For Japan as for the U.S., this pattern appears consistent with the view - which we call the news view- that improvements in productivity are generally anticipated by market participants due to a lag between the recognition of a technological 
innovation and its eventual impact on productivity.

\subsection{Lessons for Macroeconomic Fluctuations}

The observation that our estimates of $\epsilon_{2}$ and $\widetilde{\epsilon}_{1}$ are highly correlated and induce similar impulse responses suggests that news about future technological developments may be a relevant driving force behind business cycle fluctuations. In Beaudry and Portier [2004b], it is shown that, in the U.S., output, consumption, investment and hours worked respond positively to this shock and exhibit dynamics characteristic of business cycles.

Let us proceed to similar estimation for Japan. To that end, we estimate the following truncated moving average representation for different variables $Z_{t}$ :

$$
\Delta Z_{t}=\sum_{j=0}^{J} \phi_{j}^{u} u_{t-j}+\mu_{t}
$$

where $Z$ will either be consumption (C), investment (I), output $(C+I)$ or hours $(H), u$ is either $\epsilon_{2}$ or $\widetilde{\epsilon_{1}}$ and where $\mu$ is a variable-specific disturbance that is orthogonal to $u$. The resulting sequence given by $\sum_{j=0}^{n} \phi_{j}$ provides an estimate of the impulse response function of $X$ to a $u$ shock, that is, the response to what we claim may be a news shocks. The truncation is done for $J=5$.

Figure 5 displays the responses of consumption, investment, output (defined as $C+I$ ) and hours to $\epsilon_{2}$ and $\widetilde{\epsilon}_{1}$, that is, the responses to what we suggest may reflect news of a technological innovation which only diffuses slowly into productive system. As can be seen in the Figure, the responses to both shocks are very similar. Consumption and Hours increase by about $.5 \%$ on impact, while the impact response of Investment and Output is more modest. After one year, all responses are above one percentage point, except for consumption that, as expected, reacts more smoothly.

As in the case of U.S. data, these results suggest that a stock prices innovation, $\epsilon_{2}$, (i) creates business cycle like fluctuations, (ii) does not affect TFP contemporaneously and (iii) affects TFP in the long run. This pattern is consistent with the interpretation of $\epsilon_{2}$ as being primarily a news shock. Such a structural interpretation is supported by the fact that the responses of the economy to $\epsilon_{2}$ and $\widetilde{\epsilon}_{1}$ are very similar.

\subsection{Accounting for the Japanese "Lost Decade"}

Here we use the estimated VECMs to decompose historical movements into components explained by the various epsilons. Formally, and using the short run identification as an example, we start 
from the estimated VAR:

$$
\left(\begin{array}{c}
\Delta T F P_{t} \\
\Delta S P_{t}
\end{array}\right)=\widehat{A}(L)\left(\begin{array}{c}
\Delta T F P_{t} \\
\Delta S P_{t}
\end{array}\right)+\Pi\left(\begin{array}{c}
T F P_{t-1} \\
S P_{t-1}
\end{array}\right)+C+\left(\begin{array}{c}
\epsilon_{1, t} \\
\epsilon_{2, t}
\end{array}\right)
$$

where $C$ is a vector of constant term and $\Pi$ is the cointegration coefficients vector. Starting from the observed initial conditions for $T F P$ and $S P$, we can construct the series $T F P^{\epsilon_{2}}$ and $S P^{\epsilon_{2}}$ of the variations of $T F P$ and $S P$ explained by $\epsilon_{2}$ only (in other words what would have happened absent of $\epsilon_{1}$ shocks) as

$$
\left(\begin{array}{c}
\Delta T F P_{t}^{\epsilon_{2}} \\
\Delta S P_{t}^{\epsilon_{2}}
\end{array}\right)=\widehat{A}(L)\left(\begin{array}{c}
\Delta T F P_{t}^{\epsilon_{2}} \\
\Delta S P_{t}^{\epsilon_{2}}
\end{array}\right)+\Pi\left(\begin{array}{c}
T F P_{t-1}^{\epsilon_{2}} \\
S P_{t-1}^{\epsilon_{2}}
\end{array}\right)+C+\left(\begin{array}{c}
0 \\
\epsilon_{2, t}
\end{array}\right)
$$

The same computation can be done for the shock $\widetilde{\epsilon}_{1}$. The idea is then to use such expressions to decompose observed Japanese fluctuations in a meaningful way.

Figure 6 displays the series of estimated $\epsilon_{2}$ and $\widetilde{\epsilon}_{1}$, which are, as stated earlier, very similar. We observe that two large negative shocks hit the Japanese economy in 1990 and 1992. According to the short identification schemes, those shocks $\epsilon_{2}$ are negative innovations to the stock market. But those shocks are also $\widetilde{\epsilon}_{1}$ shocks, and according to the long run identification, they are downward revisions of the long run level of TFP.

It is interesting to put this observation in perspective with the conclusions of Hayashi and Prescott [2002]. As they wrote in the conclusion of their study,

" In examining the virtual stagnation that Japan began experiencing in the early 1990s, we find that the problem is not a breakdown of the financial system [...]. The problem is low productivity growth. [...] We said very little about the "bubble" period of the late 1980s and early 1990s, a boom period when property prices soared, investment as a fraction of GDP was unusually high, and output grew faster than in any other years in the 1980s and 1990s. We think the unusual pickup in economic activities, particularly investment, was due to an anticipation of higher productivity growth that never materialized. To account for the bubble period along these lines, we need to have a model where productivity is stochastic and where agents receive an indicator of future productivity." (page 227-228)

The model the authors are describing is indeed a "news" type of model, in the spirit of the theoretical example we have presented earlier in the text. Note that such a model predicts collinearity between $\epsilon_{2}$ and $\widetilde{\epsilon}_{1}$, which is also what is supported by Japanese data.

Our two orthogonalized VECMs allow us to do some accounting with this type of model in mind. Let us consider the following counterfactual exercise: starting from the actual value of the series in 1989, we compte the path of TFP and $S P$ as expected in 1989, together with what would have happen if, between 1990 and 2000, all the shocks $\epsilon_{1}$ and $\epsilon_{2}$ (or $\widetilde{\epsilon}_{1}$ and $\widetilde{\epsilon}_{2}$ ) take on their realized 
values except for $\epsilon_{2,1990}$ and $\epsilon_{2,1992}$ ( or $\widetilde{\epsilon}_{1,1990}$ and $\widetilde{\epsilon}_{1,1992}$ ) which are set to zero. The resulting path are displayed on Figure 7. Panels (a) and (c) compare the actual path of TFP and SP with the expected one as of 1989 . TFP is in 2000 about 20 percentage points below the level that was expected in 1989 for 2000, SP about 1.2 log points below. Panels (b) and (d) show what would have been the path of TFP and SP absent the 1990 and 1992 shocks. Three observations can be made. First, as expected form the collinearity between $\epsilon_{2}$ and $\widetilde{\epsilon}_{1}$, the two counterfactuals are close to each other. Second, most of what did happen to TFP in the 1990s is the consequence of these two shocks. As displayed in Panels (a) and (d), the counterfactuals are far from the actual series and close to the "expected in 1989" series. In 2000, 20 percentage points out of the 23 in the difference between the actual TFP series and the "expected in 1989" series are explained by the 1990 and 1992 shocks. Third, the same results hold to a lesser extent for the stock prices: about one half (60 percentage points) of the distance between the actual $S P$ series and the "expected in 1989" one is explained by the 1990 and 1992 shocks, the other half being mainly explained by the 1995 and 1996 shocks.

What do we learn from this exercise: two stock market shocks at the beginning of the 1990s, that where possibly the consequence of bad news about future TFP, explain most of TFP changes in the 1990s and about half of the stock market variations. This accounting exercise says nothing about the cause of those two shocks. The resolution of this question is still a puzzle for analysts of the Japanese economy.

\section{Sectoral Results For The U.S.}

In this section, we focus on the U.S. economy. The shock $\epsilon_{2}$, that is identified as the stock prices innovation in a $(T F P, S P)$ VECM (that is the shock that is orthogonal to current TFP, where TFP is measured in the Nonfarm Private Business sector), has been shown to be explaining most of the long run variance of TFP. It is of interest to go deeper in the inspection of the TFP impact and long run response to this shock in order to give some direction for a further, more structural, exploration. It is of particular interest to inspect the response of different sectors to that shock.

In this section, we make use of the BLS Multifactor Productivity Trends in Manufacturingpublished data for 20 SIC 2-digit Manufacturing 4 . We estimate the sectoral TFP response to an aggregate stock prices innovation following a two-step procedure. We first estimate an aggregate $\epsilon_{2}$ shock, as explained in section 2. We then project each sectoral productivity $T F P^{s}$, where $s$

\footnotetext{
${ }^{4}$ As obtained from http://www.bls.gov/mf p/home.htm
} 
indexes the sector, on present and past values of $\epsilon_{2}$

$$
\Delta T F P_{t}^{s}=\sum_{j=0}^{J} \phi_{j} \epsilon_{2, t-j}+\mu_{t}
$$

where $\mu$ a variable-specific disturbance that is orthogonal to $\epsilon_{2}$. The resulting sequence given by $\sum_{j=0}^{n} \phi_{j}$ provides an estimate of the impulse response function of $T F P^{s}$ to a $\epsilon_{2}$ shock. We truncate at $J=10$, and our sample runs from 1951 to 2000 .

Table 1 displays the impact and long run response of sectoral TFP to a one-standard-deviation news shock, together with the p-values associated to the tests $\phi_{0}=0$ ("impact") and $\sum_{j=0}^{10} \phi_{j}=0$ ("long run"). The estimated responses are displayed on Figure 8. Note that we have used the same scale for all the panels of the figure. According to the "news" interpretation we have proposed, the impact response should be zero, while the long run response should be positive, at least for those sectors that have been driving aggregate TFP growth for the postwar period. What do we obtain? Neither Manufacturing TFP as a whole, nor TFP in either the Nondurable or Durable sector significantly increase on impact. When one goes to the two-digit series, it is only in one out of 18 sectors - which is Transportation Equipment - that the impact response is significantly different from zero at $5 \%$ level (note that this impact effect is negative). Therefore, one cannot interpret the zero response of aggregate TFP as the result of some complex aggregation effect. As far as the long run is concerned, TFP in Manufacturing, Nondurable goods and Durable goods all respond positively, although the long run response of TFP in the Nondurable good sector is not significantly positively at $5 \%$ level. Furthermore, most of the two digit sectors (14 out of 18, the exceptions being Food \& Kindred Products, Textile Mills Products, Lumber \& Wood Products and Furniture $\&$ Fixtures ) respond positively to the shock in the long run.

Of particular interest is the observation that the stock market innovation $\epsilon_{2}$ predicts a significant long run response of TFP in the sectors that are generally considered to have been driving U.S. growth over the last 40 years. These sectors are Industrial Machinery $\&$ Computer Equipment, Electric 8 Electronic Equipment, Transportation Equipment, Instruments (at 6.6\%) for durable goods, Petroleum Refining and Rubber 6 Plastic Products (at 16\%) for nondurable goods. In all these sectors, the long run response to the stock price innovation is very strong. These results give support to the interpretation of the stock prices innovation as news about future TFP growth in the equipment sectors. 


\section{Conclusion}

The objective of this paper was to use aggregate Japanese data and sectoral U.S. data to further explore the "news view" of business cycles. According to this view, permanent movements in TFP are mainly predictable and show up first in forward looking variables like stock market prices. This view, for which we found support earlier using postwar U.S. data, also finds support using the last forty years of Japanese data. In the Japanese case, such "news" shocks are again observed to create business cycle movements in economic activity. We also used this methodology to propose an accounting exercise of the Japanese lost decade. Our finding is that about one half of the stock market fall in the 1990s is indeed the mirror image of downward revisions of future TFP. Going back to U.S. data, we show that the news about future aggregate TFP is not some artifact due to aggregation, as the stock prices news is indeed a shock that does not affect U.S. sectoral TFPs on impact, but that increases TFP in the long run in the sectors that are driving U.S. TFP growth, namely durable goods, and among them equipment sectors.

\section{References}

Beaudry, P., And F. Portier (2004a): “An Exploration into Pigou's Theory of Cycles,” Journal of Monetary Economics, 51(6), 1183-1216.

(2004b): "News, Stock Prices and Economic Fluctuations," Working Paper 10548, National Bureau of Economic Research.

Blanchard, O., and D. Quah (1989): "The Dynamic Effects of Aggregate Demand and Supply Disturbances," The American Economic Review, 79(4), 655-673.

DoAn, T. (1992): Rats Manual. Estima, Evanston, IL.

Hairault, J., F. Langot, and F. Portier (1997): "Time to Implement and Aggregate Fluctuations," Journal of Economics Dynamics and Control, 22, 109-21.

Hayashi, F., And E. Prescott (2002): "Japan in the 1990s: A Lost Decade," Review of Economic Dynamics. 


\section{Appendix}

\section{A Solution to the Models of Section 2.2}

A Simple Optimal Growth Model with Technology and Preference Shocks: In order to maximize its profit, the firm equalizes marginal products of inputs with their marginal costs

$$
\begin{aligned}
(1-\gamma) \frac{Y_{t}}{L_{t}} & =w_{t} \\
\gamma \frac{Y_{t}}{K_{t}} & =\kappa_{t}
\end{aligned}
$$

Denoting $\chi_{t}$ the Lagrange multiplier of the households budget constraint, maximization of intertemporal utility leads to the following first order conditions:

$$
\begin{aligned}
\frac{1}{C_{t}} & =\chi_{t} \\
\Lambda_{t} L_{t}^{\sigma-1} & =\chi_{t} w_{t} \\
\chi_{t} & =\beta E_{t} \chi_{t+1} \kappa_{t+1}
\end{aligned}
$$

Combining those equations, we obtain the following recursion:

$$
\frac{I_{t}}{C_{t}}=\alpha \beta+\alpha \beta E_{t} \frac{I_{t+1}}{C_{t+1}}
$$

Solving forward and imposing the usual transversality condition leads to

$$
\begin{aligned}
C_{t} & =(1-\beta \gamma) Y_{t} \\
I_{t} & =\beta \gamma Y_{t}
\end{aligned}
$$

On the other hand, equilibrium labor is obtained from labor demand and intratemporal first order conditions of the household program:

$$
L_{t}=\left(\frac{1-\gamma}{1-\beta \gamma}\right)^{1 / \sigma} \Lambda_{t}^{-1 / \sigma}
$$

The equilibrium law of motion of consumption can be easily computed and is given by ( taking logs and omitting constant terms):

$$
c_{t}=\log \left(\theta_{t}\right)+\gamma c_{t-1}-\frac{(1-\gamma)}{\sigma} \eta_{2, t}
$$

Since the price of bonds $P^{B}$ must satisfy the equation $P_{t}^{B} E_{t} \frac{C_{t+1}}{\beta C_{t}}=1$, the structural moving for $\triangle T F P_{t}$ and $\Delta p_{t}^{b}$ can be approximated by the following expression:

$$
\left(\begin{array}{c}
\Delta T F P_{t} \\
\Delta p_{t}^{b}
\end{array}\right)=\left(\begin{array}{cc}
1 & 0 \\
(1-\gamma) \frac{1}{1-\gamma L}-1 & -\frac{(1-L)(1-\gamma)^{2}}{\sigma(1-\gamma L)}
\end{array}\right)\left(\begin{array}{l}
\eta_{1, t} \\
\eta_{2, t}
\end{array}\right)
$$


A Model with One Period Delayed Response of Innovation on Productivity : In the model with news, first order conditions are identical to those of the RBC model, the only change being the dating of the technological innovation. As in the RBC model, consumption is given by

$$
C_{t}=\Omega Z_{t} \Lambda^{-(1-\gamma) / \sigma} C_{t-1}^{\gamma}
$$

where $\Omega$ is a constant term and where $\Lambda$ is now constant since we have assumed away preference shocks. We then have in logs, omitting constant terms:

$$
c_{t}=\gamma c_{t-1}+\log \left(\theta_{t-1}\right)+\eta_{1, t-1}-\frac{1-\gamma}{\sigma} \eta_{2, t}
$$

Since the price of bonds $P^{B}$ must satisfy the equation $P_{t}^{B} E_{t} \frac{C_{t+1}}{\beta C_{t}}=1$, the structural moving for $\Delta T F P_{t}$ and $\Delta p_{t}^{b}$ is approximately given by the following expression:

$$
\left(\begin{array}{c}
\Delta T F P_{t} \\
\Delta p_{t}^{b}
\end{array}\right)=\left(\begin{array}{cc}
L & \frac{\gamma(1-L)}{(1-\rho L)} \\
\frac{(1-\gamma) L}{1-\gamma L}-1 & \frac{(-\rho)(1-L)}{(1-\rho L)}
\end{array}\right)\left(\begin{array}{c}
\eta_{1, t} \\
\eta_{2, t}
\end{array}\right)
$$

\section{B Tables}


Table 1: Impact and Long Term Responses of TFP to a One-Standard-Deviation Stock Prices Innovation $\epsilon_{2}$

\begin{tabular}{lcccl}
\hline \hline & Impact & (p-value) & 10 years & (p-value) \\
\hline Manufacturing & -0.1 & $(68.6 \%)$ & $2.9^{\star}$ & $(1.8 \%)$ \\
Nondur. Goods & 0.1 & $(86.8 \%)$ & 0.6 & $(61.6 \%)$ \\
Durable Goods & -0.3 & $(39.0 \%)$ & $4.6^{\star}$ & $(0.1 \%)$ \\
\hline Non Durable & & & & \\
Food \& Kindred Prod. & 0.4 & $(33.3 \%)$ & -1.0 & $(53.3 \%)$ \\
Textile Mills Prod. & 0.2 & $(65.5 \%)$ & -1.2 & $(38.3 \%)$ \\
Apparel \& Related Prod. & 0.3 & $(27.6 \%)$ & 0.1 & $(91.3 \%)$ \\
Paper \& Allied Prod. & -0.3 & $(51.1 \%)$ & 1.5 & $(43.4 \%)$ \\
Printing \& Publishing & -0.2 & $(41.2 \%)$ & 0.8 & $(48.3 \%)$ \\
Chem. \& Allied Prod. & -0.4 & $(61.1 \%)$ & 2.5 & $(35.5 \%)$ \\
Petroleum Refining & -0.0 & $(92.3 \%)$ & 1.7 & $(2.0 \%)$ \\
Rubber \& Plastic Prod. & 0.3 & $(42.1 \%)$ & 2.1 & $(15.8 \%)$ \\
Durable & & & & \\
Lumber \& Wood Prod. & -0.3 & $(58.2 \%)$ & -0.3 & $(89.2 \%)$ \\
Furniture \& Fixtures & 0.1 & $(59.7 \%)$ & -0.7 & $(45.3 \%)$ \\
Stone, Clay \& Glass & -0.1 & $(82.2 \%)$ & 1.9 & $(18.7 \%)$ \\
Primary Metal Ind. & -0.5 & $(31.8 \%)$ & 2.1 & $(26.4 \%)$ \\
Fabricated Metal Prod. & 0.1 & $(84.6 \%)$ & 0.4 & $(65.6 \%)$ \\
Ind. Machinery,Comp.Eq. & 0.3 & $(55.3 \%)$ & $5.44^{\star}$ & $(0.4 \%)$ \\
Electric \& Electr. Eq. & 0.7 & $(17.6 \%)$ & $6.3^{\star}$ & $(0.2 \%)$ \\
Transportation Equip. & $-1.2^{\star}$ & $(0.6 \%)$ & $3.6{ }^{\star}$ & $(2.4 \%)$ \\
Instruments & -0.4 & $(31.1 \%)$ & $2.5{ }^{\star}$ & $(6.6 \%)$ \\
Misc. Manufacturing & $-1.1^{\star \star}$ & $(7.6 \%)$ & 3.2 & $(14.8 \%)$ \\
\hline \hline
\end{tabular}

This table reports the point estimate of the impact and long run (10 years) response of two-digit U.S. manufacturing TFP to a shock $\epsilon_{2}$ - i.e. a SP innovation in the benchmark bivariate (TFP, SP) VECM estimated on aggregate annual U.S., with two lags and one cointegration relation. It also reports the P-value for the test that the impact and long run (10 years) response of two-digit U.S. manufacturing TFP to a shock $\epsilon_{2}$ is zero. $A \star$ indicates that the coefficient is significantly different from zero at 5\%, (10\% for $a \star \star)$. 
C Figures 
Figure 1: Impulse Responses to Shocks $\epsilon_{2}$ and $\widetilde{\epsilon}_{1}$ in the (TFP, SP) VECM, Using U.S. Data (top line) and Japanese Ones (bottom line)
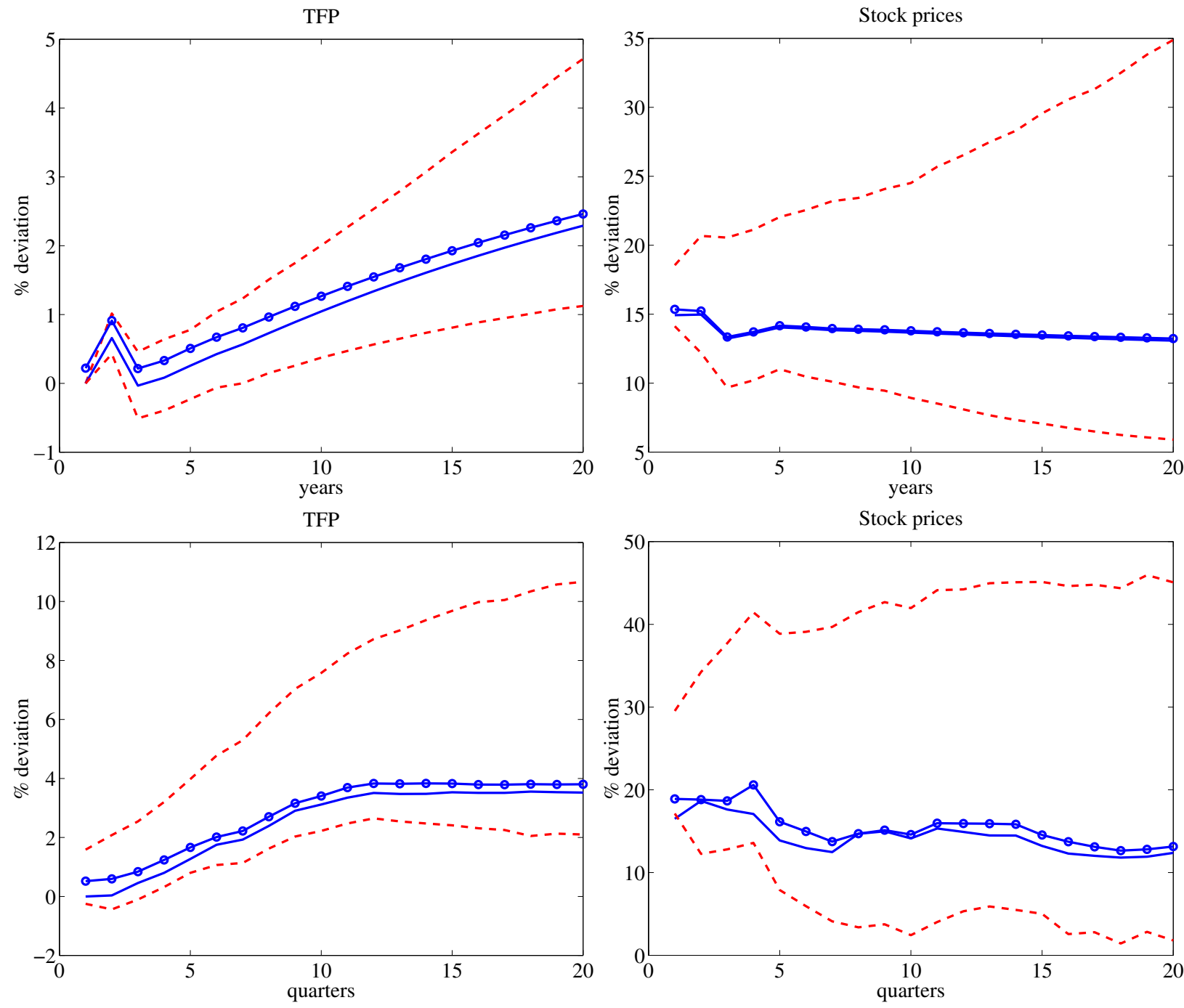

On each panel of this figure, the bold line represents the point estimate of the responses to a unit $\epsilon_{2}$ shock (the shock that does not have instantaneous impact on TFP in the short run identification); the line with circles represents the point estimate of the responses to a unit $\widetilde{\epsilon_{1}}$ shock (the shock that has a permanent impact on TFP in the long run identification). The unit of the vertical axis is percentage deviation from the situation without shock. Dotted lines represent the $10 \%$ and $90 \%$ quantiles of the distribution of the IRF in the case of the short run identification, this distribution being the bayesian simulated distribution obtained by Monte-Carlo integration with 2500 replications, using the approach for just-identified systems discussed in Doan [1992]. The top panels present the U.S. estimates, using annual observations over the period 1948-2000, the bottom panels present Japanese estimates, using annual observations over the period 1960-2000. 
Figure 2: Forecast Error Variance of TFP explained by $\epsilon_{2}$ and $\widetilde{\epsilon}_{1}$, Using U.S. Data (left panel) and Japanese Ones (right panel)


This figure displays the share of TFP forecast error variance attributed to $\epsilon_{2}$ (the shock that does not have instantaneous impact of TFP in the short run identification) and to $\widetilde{\epsilon}_{1}$ (the shock that has a permanent impact on TFP in the long run identification).

Figure 3: $\epsilon_{2}$ Against $\widetilde{\epsilon}_{1}$ in the (TFP, SP) VECM, Using U.S. Data (left panel) and Japanese Ones (right panel)
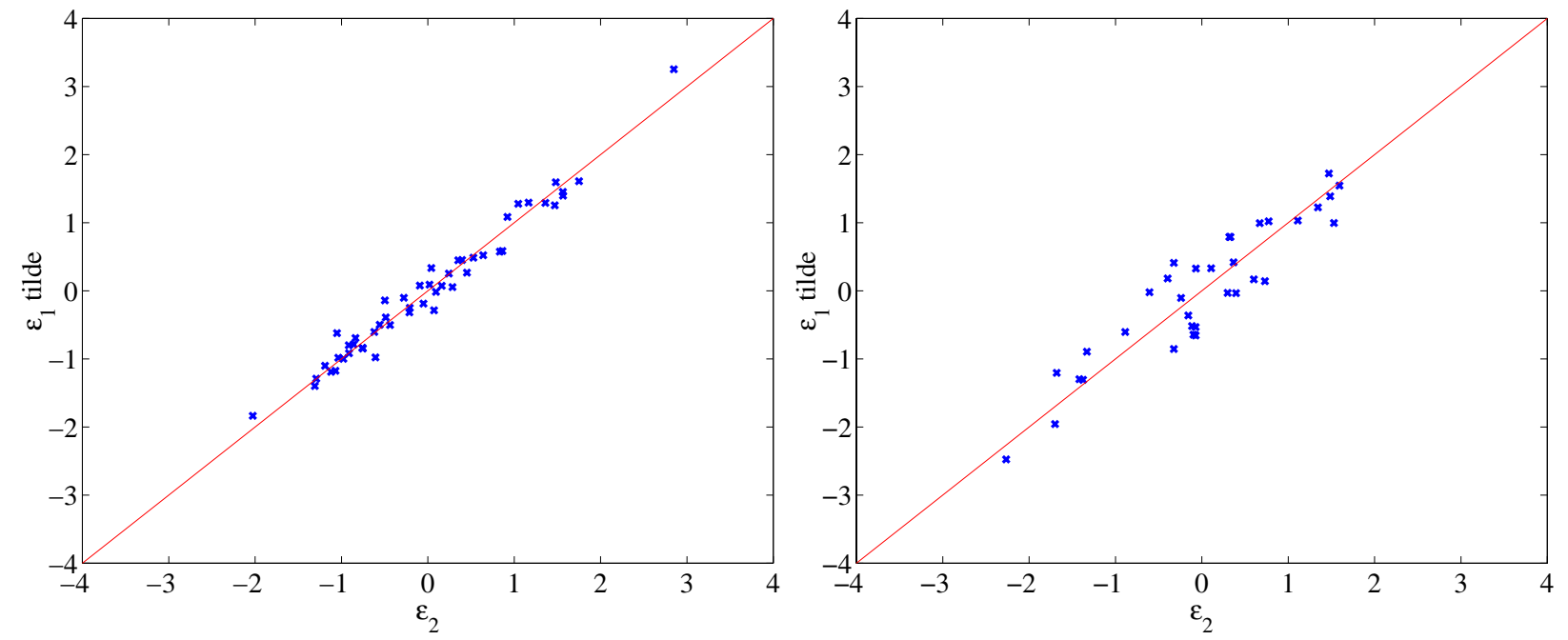

Each panel of this figure plots $\epsilon_{2}$ against $\widetilde{\epsilon}_{1}$. Both shocks are obtained from the baseline (TFP, SP) VECM of each country. The straight line is the $45^{\circ}$ line. 
Figure 4: Impulse Responses to Shocks $\epsilon_{2}$ and $\widetilde{\epsilon}_{1}$ in the Japanese (TFP, SP) VECM, for different choices of lag length.
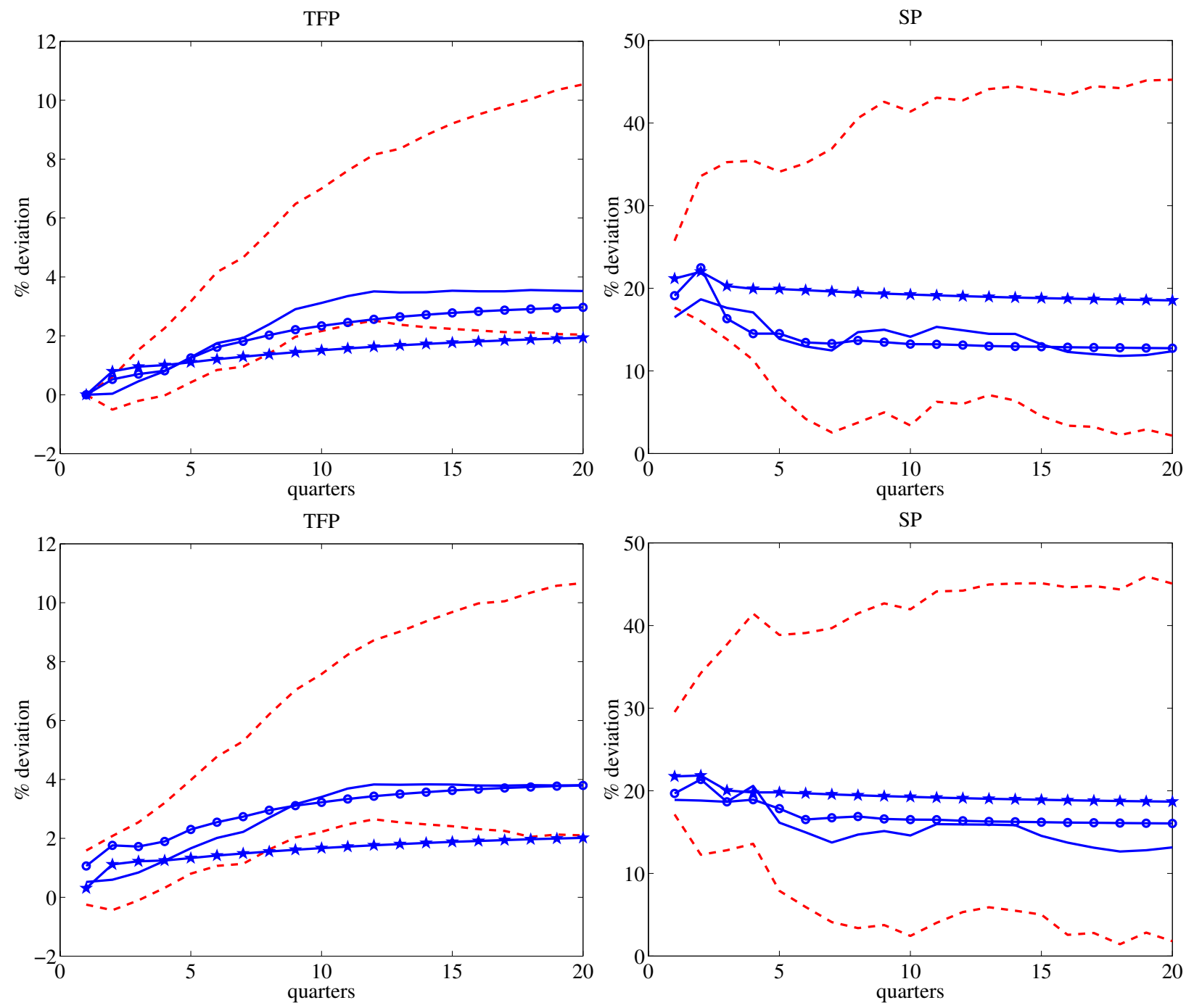

The top panels of this figure present responses to a unit $\epsilon_{2}$ shock (the shock that does not have instantaneous impact on TFP in the short run identification); the bottom panels present responses to a unit $\widetilde{\epsilon_{1}}$ shock (the shock that has a permanent impact on TFP in the long run identification). On each panel of this figure, the bold line represents the point estimate in the benchmark specification (six lags), the lines with stars represents the point estimate when one lag is chosen, and the line with circle the point estimate with two lags. The unit of the vertical axis is percentage deviation from the situation without shock. Dotted lines represent the $10 \%$ and $90 \%$ quantiles of the distribution of the IRF in the benchmark case (six lags), this distribution being the bayesian simulated distribution obtained by Monte-Carlo integration with 2500 replications, using the approach for just-identified systems discussed in Doan [1992]. 
Figure 5: Response of Consumption, Investment, Output (Defined as $C+I$ ) and Hours to $\epsilon_{2}$ and $\widetilde{\epsilon}_{1}$ in the $(T F P, S P)$ VECM, Japanese Annual Data
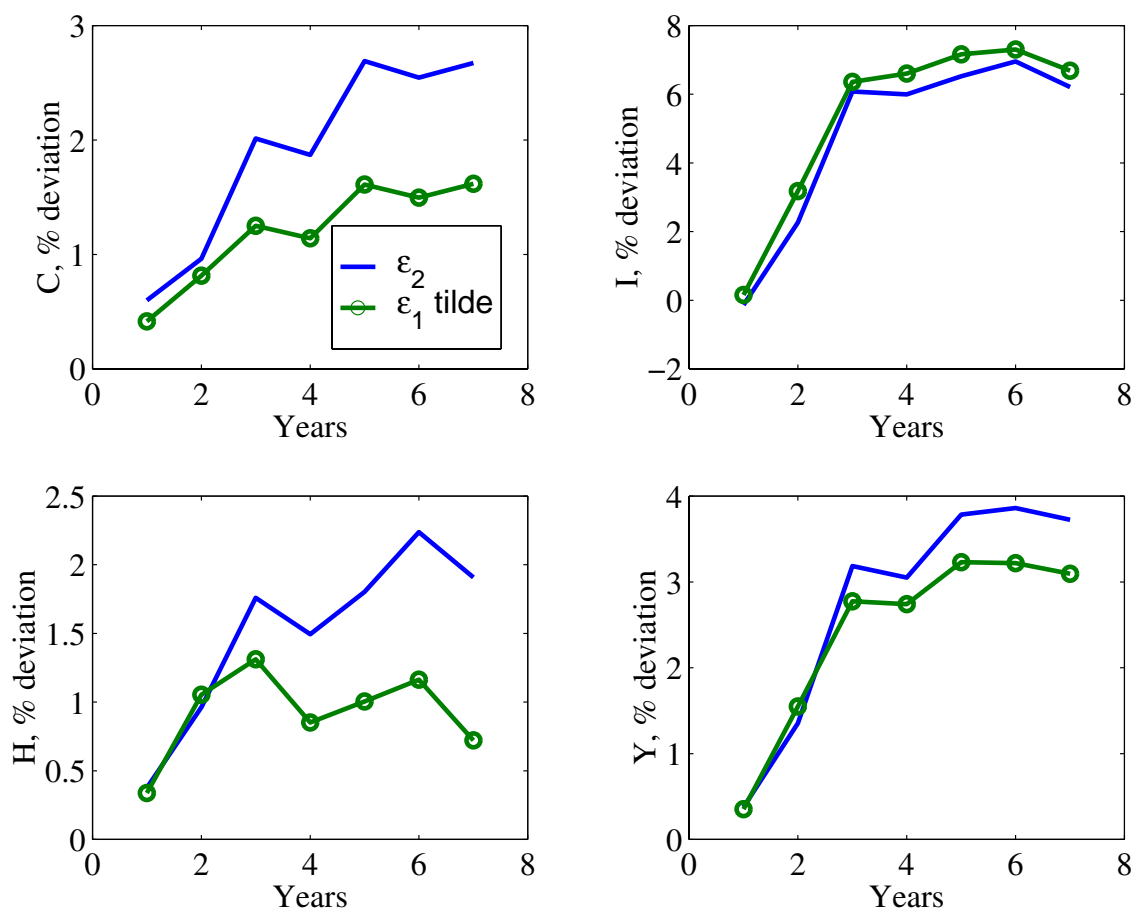

This figure displays the response of Consumption, Investment, Output (defined as $C+I$ ) and Hours to a unit $\epsilon_{2}$ shock (the shock that does not have instantaneous impact on TFP in the short run identification) or to a unit $\widetilde{\epsilon}_{1}$ (the shock that has a permanent impact on TFP in the long run identification). The unit of the vertical axis is percentage deviation from the situation without shock. The shocks have been estimated with the benchmark (TFP,SP) Japanese VECM, with six lags and one cointegrating relation. 
Figure 6: Estimated $\epsilon_{2}$ and $\widetilde{\epsilon}_{1}$ in the $(T F P, S P)$ VECM, Japanese Annual Data

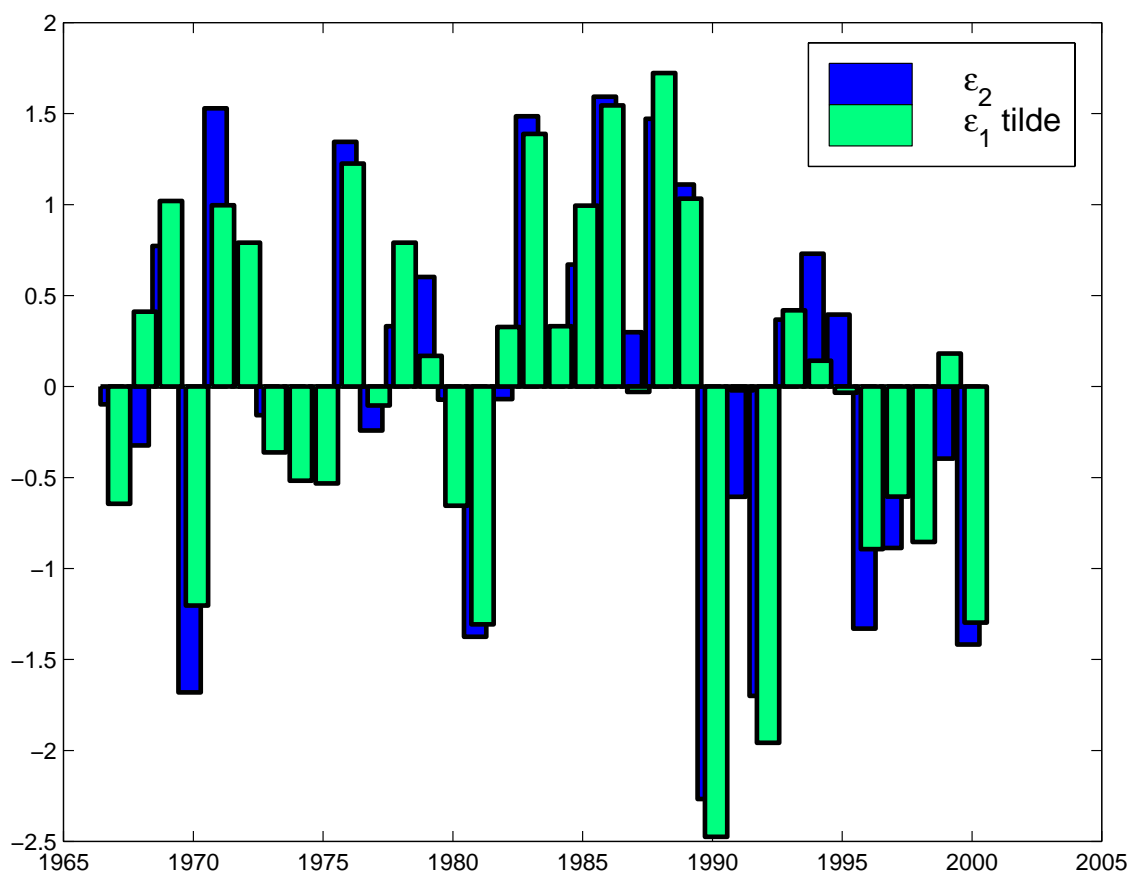

This figure plots $\epsilon_{2}$ and $\widetilde{\epsilon}_{1}$. Both shocks are obtained from the baseline (TFP, SP) VECM, with six lags and one cointegrating relation. 
Figure 7: Historical Decomposition of the 1990s, (TFP, SP) VECM, Japanese Annual Data

(a)

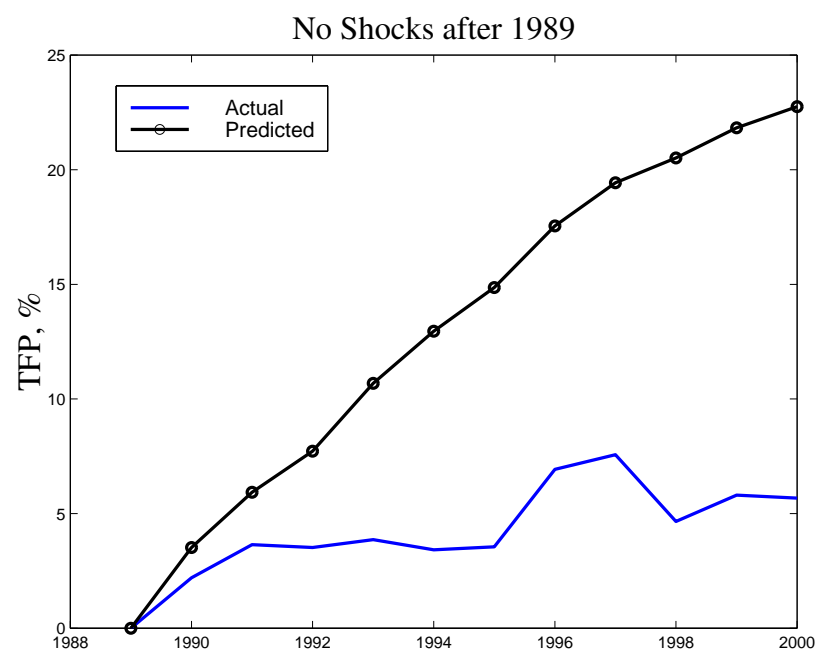

(c)

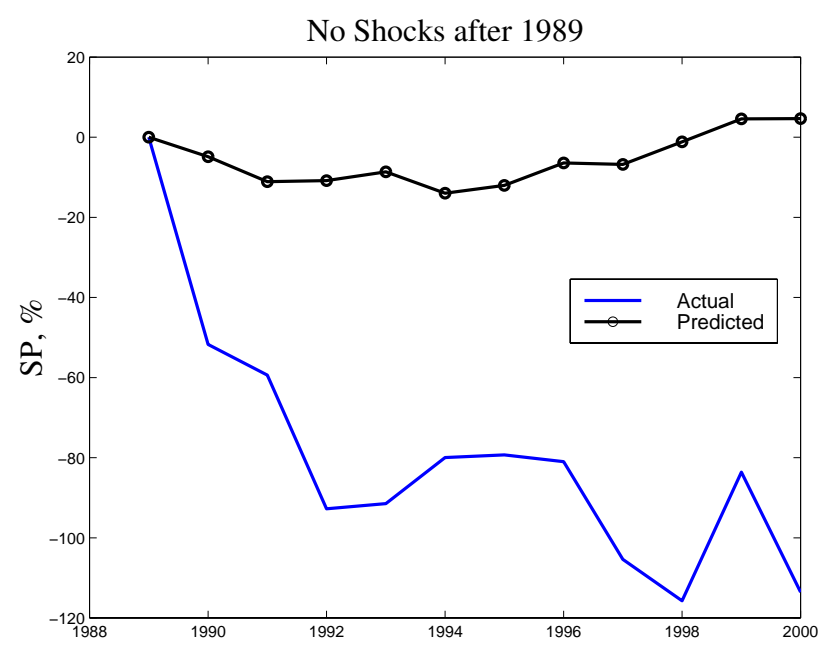

(b)

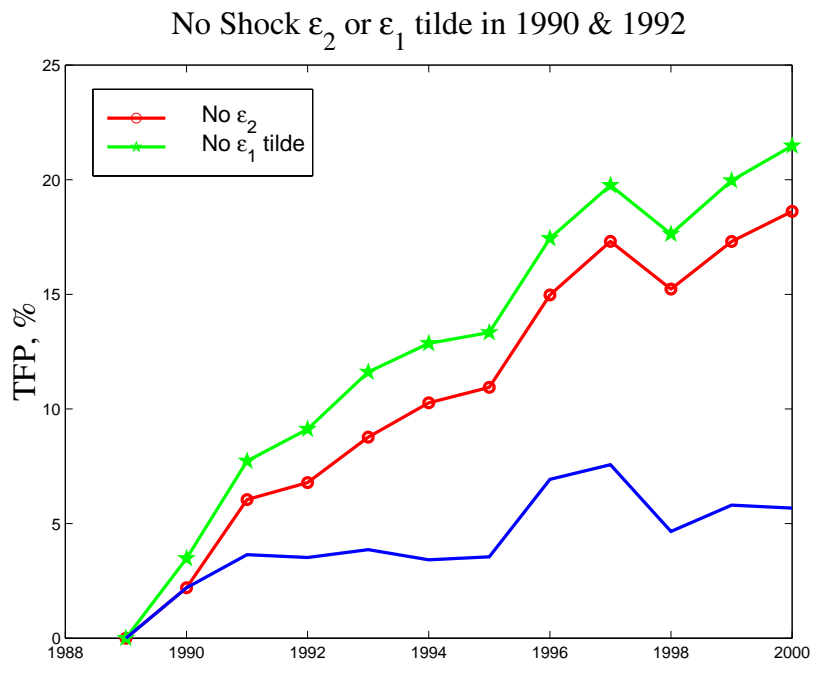

(d)

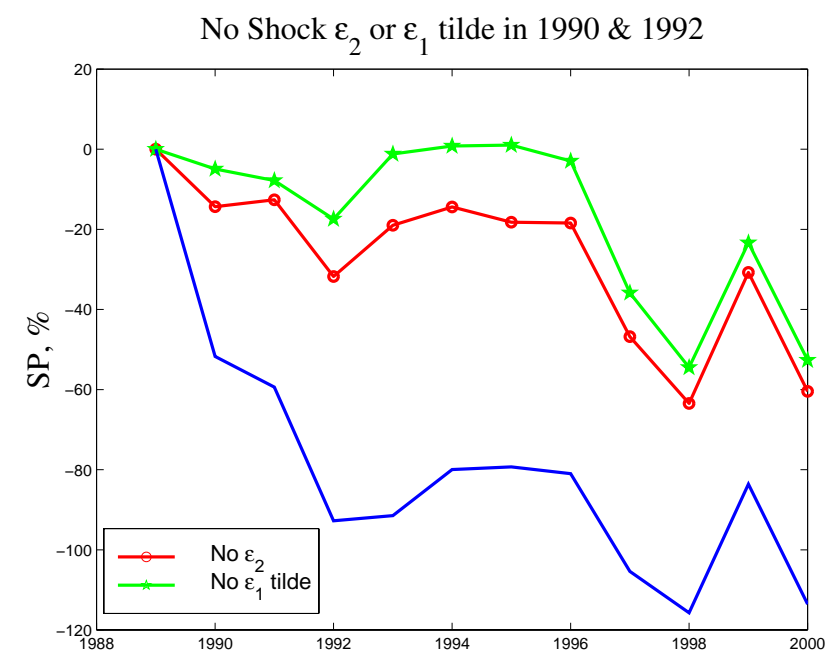

This figure plots the decomposition of TFP and SP into movements explained by some various combinations of structural shocks. In panel (a) and (c) are compared the actual path of the series with the path expected in 1989 (in other words what would have happen absent of all shocks after 1989). In panel (b) and (d) are compared the actual series and the series obtained with all shocks except the structural shocks $\epsilon_{2}$ or $\widetilde{\epsilon}_{1}$ in 1990 and 1992. Results are obtained from the baseline (TFP, SP) VECM, with six lags and one cointegrating relation. 
Figure 8: U.S. Sectoral TFP Responses To a Stock market Innovation $\epsilon_{2}$

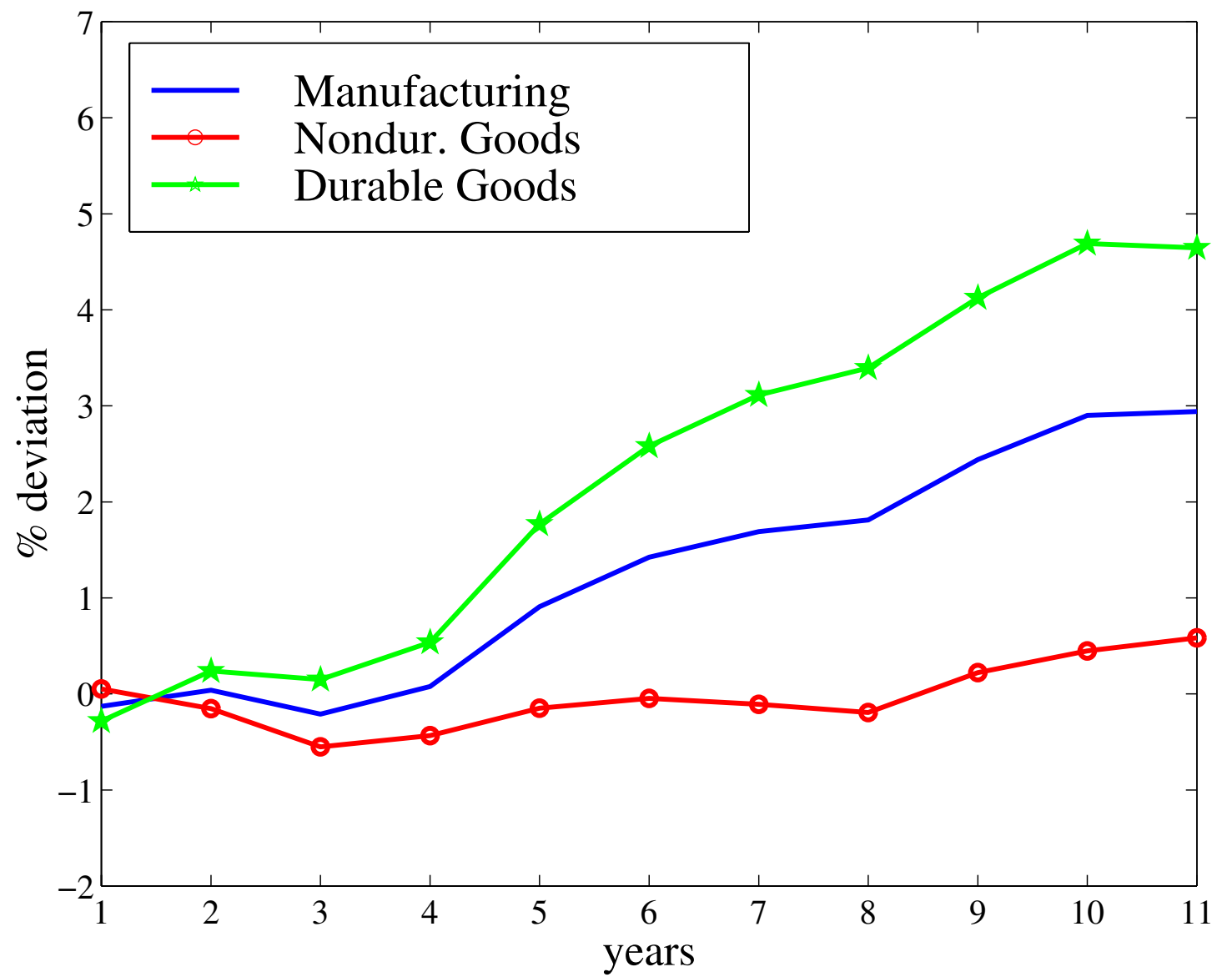

This figure displays the response of Manufacturing, Nondurable and Durable goods sectoral TFP to a unit $\epsilon_{2}$ shock (the shock that does not have instantaneous impact on aggregate TFP in the short run identification). The unit of the vertical axis is percentage deviation from the situation without shock. 
Figure 9: U.S. Sectoral TFP Responses To a Stock market Innovation $\epsilon_{2}$, 2-digit level
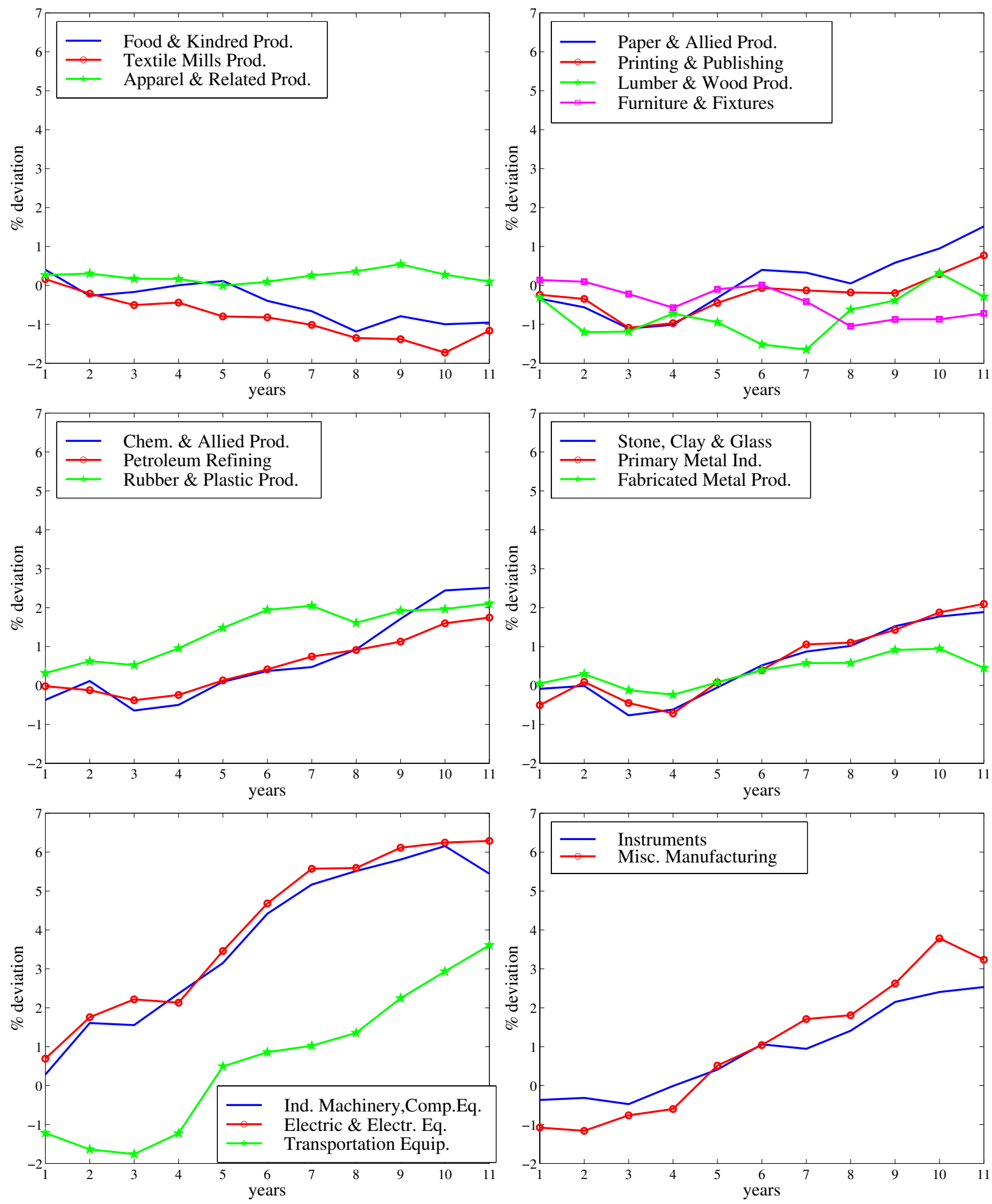

This figure displays the response of the considered sectoral TFP to a unit stock prices innovation $\epsilon_{2}$ (the shock that does not have instantaneous impact on aggregate TFP in the short run identification). The unit of the vertical axis is percentage deviation from the situation without shock. 